\title{
Modeling of hot-point drilling in ice
}

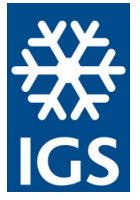

Article

Cite this article: Li Y, Talalay PG, Fan X, Li B, Hong $J$ (2021). Modeling of hot-point drilling in ice. Annals of Glaciology 62(85-86), 360-373. https://doi.org/10.1017/aog.2021.16

Received: 6 March 2020

Revised: 7 August 2021

Accepted: 9 August 2021

First published online: 9 September 2021

\section{Key words:}

Buoyancy corrected force; cone angle; ice melting; ice temperature; power; thermal head shape; thermal model

Author for correspondence:

Jialin Hong, E-mail: hjl2398@126.com
Yazhou Li ${ }^{1}$, Pavel G. Talalay ${ }^{1}$, Xiaopeng Fan ${ }^{1}$, Bing $\mathrm{Li}^{2}$ and Jialin Hong ${ }^{1}$

${ }^{1}$ Polar Research Center, Jilin University, Changchun, Jilin 130026, China and ${ }^{2}$ School of Engineering and Technology, China University of Geosciences (Beijing), Beijing 100083, China

\section{Abstract}

Hot-point drills have been widely used for drilling boreholes in glaciers, ice caps and ice sheets. A hot-point drill melts ice through the thermal head at its bottom end. Penetration occurs through a close-contact melting (CCM) process, in which the ice is melted, and the meltwater is squeezed out by the exerted force applied on the thermal head. During the drilling, a thin water film is formed to separate the thermal head from the surrounding ice. For the hot-point drill, the rate of penetration (ROP) is influenced by several variables, such as thermal head shape, buoyancy corrected force (BCF), thermal head power (or temperature) and ice temperature. In this study, we developed a model to describe the CCM process, where a constant power or temperature on the working surface of a thermal head is assumed. The model was developed using COMSOL Multiphysics 5.3a software to evaluate the effects of different variables on the CCM process. It was discovered that the effect of thermal head shape and the cone angle of conical thermal head on ROP is less significant, whereas the increase in the BCF and the power (or temperature) of the thermal head can continuously enhance the ROP.

\section{Nomenclature}

$A_{\mathrm{h}} \quad$ area at the working surface of the thermal head, $\mathrm{m}^{2}$

$\alpha \quad$ thermal diffusivity, $\mathrm{m}^{2} \mathrm{~s}^{-1}$

$A_{\mathrm{p}} \quad$ area at the water-ice interface, $\mathrm{m}^{2}$

$\rho$ density, $\mathrm{kg} \mathrm{m}^{-3}$

c heat capacity, $\mathrm{J} \mathrm{kg}^{-1} \mathrm{~K}^{-1}$

$\delta \quad$ thickness of the melt film, $\mathrm{m}$

$F \quad$ axial load, $\mathrm{N}$

$\mu \quad$ dynamic viscosity of water, $\mathrm{Pa} \mathrm{s}^{-1}$

$F^{*} \quad$ buoyancy corrected force, $\mathrm{N}$

$\eta \quad$ efficiency of thermal head

$g$ acceleration of gravity, $\mathrm{m} \mathrm{s}^{-2}$

$\varphi \quad$ angular position, see Figure 1

$H$ height of water column in melted borehole, $\mathrm{m}$

$\pi \quad$ circumference ratio

$k$ thermal conductivity, $\mathrm{W} \mathrm{m}{ }^{-1} \mathrm{~K}^{-1}$

$(o-x y)$ Cartesian coordinate system

$L$ maximum heat disturbance distance, $\mathrm{m}$

$\left(o^{\prime}-h s\right)$ local coordinate system

$L_{\mathrm{m}} \quad$ latent heat of melting, $\mathrm{J} \mathrm{kg}^{-1}$

$\Gamma_{\mathrm{h}} \quad$ working surface of the thermal head

$p \quad$ pressure in the melt film, $\mathrm{Pa}$

$\Gamma_{\mathrm{w}} \quad$ outflow boundary of the melt film

$P \quad$ input power, $\mathrm{W}$

$\Gamma_{\mathrm{p}} \quad$ water-ice interface

$P_{\mathrm{E}} \quad$ power used for ice melting, $\mathrm{W}$

$\Gamma_{\mathrm{i}} \quad$ non-heat-disturbed isothermal virtual surface in ice

$P_{\mathrm{L}} \quad$ power loss, $\mathrm{W}$

$q_{\mathrm{h}} \quad$ heat flux of the thermal head, $\mathrm{W} \mathrm{m}^{-2}$

$R \quad$ radius of the thermal head, $\mathrm{m}$

$T$ Temperature, $\mathrm{K}$

$T_{\mathrm{h}} \quad$ temperature of the thermal head, $\mathrm{K}$

$T_{\mathrm{i}} \quad$ ice temperature, $\mathrm{K}$

$T_{\mathrm{m}} \quad$ melting point temperature, $\mathrm{K}$

$T_{\mathrm{w}} \quad$ average temperature of the melt film, $\mathrm{K}$

$u$ tangential velocity, $\mathrm{m} \mathrm{s}^{-1}$

$u_{\max }$ maximum value of the tangential velocity, $\mathrm{m} \mathrm{s}^{-1}$

$v$ normal velocity, $\mathrm{m} \mathrm{s}^{-1}$

$V \quad$ penetration rate, $\mathrm{m} \mathrm{s}^{-1}$

\section{Subscripts}

water $w\left(\rho_{\mathrm{w}}, c_{\mathrm{w}}, k_{\mathrm{w}}, \alpha_{\mathrm{w}}\right)$

ice $\quad i\left(\rho_{\mathrm{i}}, c_{\mathrm{i}}, k_{\mathrm{i}}, \alpha_{\mathrm{i}}\right)$ 


\section{Introduction}

Since hot-point drills were first proposed by Weinberg (1912), they have been widely utilized in drilling boreholes in glaciers, ice caps and ice sheets for installing ablation sticks, determining ice thickness, locating englacial and subglacial streams, and measuring the temperature and other internal features of glaciers (Nizery, 1951; Gerrard and others, 1952; Sukhanov and others, 1974; Gillet, 1975; Hooke, 1976). In recent years, hot-point drills were also proposed for exploring ice-covered aquatic systems in Antarctica and on extraterrestrial planets, such as Saturn's moon, Enceladus, and Jupiter's moon, Europa (Lorenz, 2012; Stone and others, 2014; Talalay and others, 2014; Horne, 2017; Dachwald and others, 2020).

Without coring, a hot-point drill melts a borehole in ice by the thermal head at its bottom tip. A thermal head could be heated through electricity or a hot fluid. In the former case, the electrically heated element can be a cartridge heater, coil heater or silicon carbide heater (LaChapelle, 1963; Wirtza and Hildebrandt, 2016). In the latter case, the thermal head is heated using circulating hot water or an antifreeze, as it is set out in Swiss Federal Institute of Technology Zürich (ETH) hot point and IceCube firn drill (Kasser, 1960; Benson and others, 2014). A material with a high thermal conductivity, such as silver or copper, is usually used in manufacturing an electrically heated thermal head, which uniformly distributes the heat generated from the heaters to this working surface. The input power on the working surface of the thermal head remains constant during the drilling process, and the heat flux remains equal on all the parts of the working surface. This working condition is known as a power-driven condition (PDC). Alternatively, the temperature on the working surface of the hot-fluid-heated thermal head can be considered to be constant; this working condition with an isothermal working surface on the thermal head is called a temperature-driven condition (TDC). It should be noted that PDC and TDC can only be identified based on the condition of the working surface of the thermal head instead of the heat medium applied through the thermal head. For example, in some cases, the working surface of an electrically heated thermal head can also be isothermal and works in TDC mode (Shreve, 1962). Based on this classification, the working state for different thermal heads can be described better, and the details are given below.

The following parameters influence the rate of penetration (ROP) of a thermal head: power or temperature of the thermal head, buoyancy corrected force (BCF) on the thermal head, ice temperature, distribution of heaters, and material and shape used for producing the thermal head (Talalay and others, 2019). Currently, there is no standard guidance for designing optimal thermal heads, and several researchers have relied on experimental methods in identifying the optimal configuration of thermal heads and for investigating the drilling performance in the field, which is expensive and time-consuming (Treffer and others, 2006; Weiss and others, 2008; Talalay, 2020). Therefore, it is necessary to apply theoretical modeling techniques in evaluating the ice drilling-melting process before producing and testing an actual thermal head.

During the drilling process using hot points, ice is melted, and the melted water is then squeezed out by an exerted force applied on the thermal head. Consequently, a thin water film is formed between the thermal head and the borehole bottom, resulting in a complex heat transfer between thermal head and ice. The first theoretical method used to study this heat transfer system was based on a simple macro-scale power balance method (Aamot, 1967). Later, more accurate close-contact melting (CCM) phenomena were used to describe the ice-melting process (e.g. Zotikov and others, 1974).

A CCM phenomenon usually occurs when a solid heat source is pressed against a phase change material (PCM) with a lower melting point temperature (Mayer and Moaveni, 2008). The CCM process can be caused by a temperature rise in the PCM (Chen and others, 2008) or a decreased PCM melting point under high pressure (Bejan and Tyvand, 1992; Chen and others, 2005). The CCM phenomenon commonly occurs in several applications (Moallemi and Viskanta, 1985). For example, the 'selfburial' of nuclear waste materials and the 'melt-down' of reactor cores in the nuclear industry are typical cases of CCM processes (Jansen and Stepnewski, 1973; Logan, 1974). Another similar situation occurs during hot welding (Jackson, 1965; Toshiyuki and Giedt, 1982). In the field of geology, magma flow in the Earth's interior can be regarded as a CCM process (Birth, 1975; Marsh, 1978). Additionally, a thermal storage system with a PCM can also be seen as a CCM phenomenon (Roy and Sengupta, 1987; Hirata and others, 1991; Hu and others, 1999; Kumano and others, 2005a).

CCM theories have been established in the past decades, and various models have been developed to describe the CCM process by considering the heat source configurations, such as a flat surface (Moallemi and others, 1986; Yoo, 2000), a sphere (Emerman and Turcotte, 1983) and even an elliptical cylinder (Roy and Sengupta, 1990). However, a few models can be used to describe the CCM processes that are directly related to ice drilling. Shreve (1962) investigated the CCM process in ice drilling by assuming an isothermal working surface on a thermal head. In Shreve's model, a shape factor and a drilling performance number were given to evaluate the drilling performance of the thermal head. However, the effect of a single variable, such as thermal head temperature, BCF or ice temperature, was not considered. Later, additional models of the CCM process were developed to optimize the shape of the thermal head (Salamatin and others, 1984; Pudovcin and others, 1988; Fomin and Cheng, 1991). In these models, more attention was paid to the shape of the thermal head, but the effects of other variables were neglected. More recently, Schüller and Kowalski (2019) investigated the effect of power, BCF and ice temperature on the drilling performance by analyzing the CCM process with respect to extraterrestrial ice. In their study, the shape effect of the thermal head was not considered, and the developed model could only be applied to PDCs.

In general, the ice-melting process was not comprehensively discussed in previous CCM models in terms of variation in parameters such as water-film thickness, distribution of pressure and flow velocity in melt films, heat loss and range of heat disturbance. In addition, the effects of thermal head shape, cone angle of conical thermal head, input power, BCF and ice temperature on ROP were not evaluated fully.

In this paper, we present a new approach by combining the conventional CCM model with a macro-scale power balance method established by Aamot (1967). An analytical-numerical hybrid method is applied to solve the model using COMSOL Multiphysics 5.3 a software. The ice-melting process of the thermal head is analyzed to determine the effects of the thermal head shape, cone angle of conical thermal head, BCF, power (or temperature) of the thermal head and ice temperature on ROP under both PDC and TDC. The variation in water-film thickness, distribution of the pressure and flow velocity in the melt film, temperature (heat flux) distribution of the thermal head, heat loss and the range of heat disturbance in ice are also evaluated.

\section{Model development}

\subsection{Physical model}

The CCM process of thermal drilling in ice is illustrated in Figure 1. A thermal head is heated setting constant temperature $T_{\mathrm{h}}$ or constant power $P$ at its outer surface $\Gamma_{\mathrm{h}}$ to melt the 


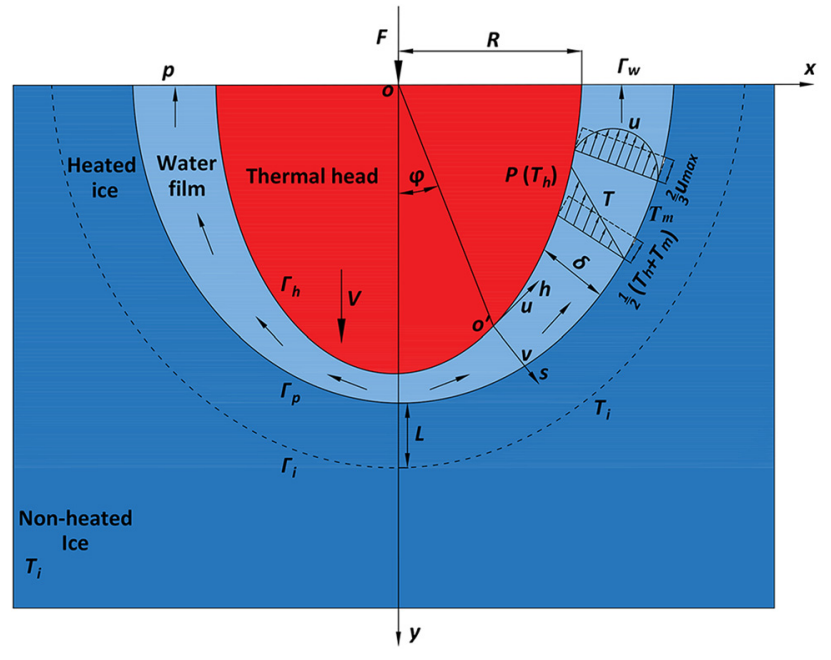

Fig. 1. Schematic of the CCM process during thermal drilling in ice.

surrounding ice. Then, the meltwater is squeezed out by applying an axial load $F$ acting on the thermal head. Consequently, a thin water film with a thickness of $\delta$ is formed, and the thermal head is separated from the ice by the water film. With the water film flowing out from its boundary $\Gamma_{\mathrm{w}}$, the thermal head starts to decent in ice at a velocity of $V$. The temperature at the interface between the water film and ice $\Gamma_{\mathrm{p}}$ is equal to the melting point temperature of the ice $T_{\mathrm{m}}$. The water pressure $p$ on the outflow boundary of the water film $\Gamma_{\mathrm{w}}$ equals to hydrostatic water pressure in the borehole.

During the ice-drilling process, the ice around the thermal head is first heated before being melted. An isothermal virtual surface $\Gamma_{\mathrm{i}}$, which is the border of the heated ice at the temperature of $T_{\mathrm{i}}$, exists at a specific distance from the bottom. The distance between the isothermal virtual surface and the water-ice interface just below the center of the thermal head $L$ can be used to evaluate the heat disturbance range in the ice caused by the thermal head during the drilling process. We define a Cartesian coordinate system $(o-x y)$ and a local coordinate system $\left(o^{\prime}-h s\right)$ in our model to describe the CCM process. The origin of the Cartesian coordinate system is fixed at the center of the thermal head, while that of the local coordinate system changes along the outer surface of the thermal head. The parameters $u$ and $v$ are the velocity components of the water film in the $h$-direction and $s$-direction, respectively.

Some assumptions have been made regarding the behavior of the physical process in melt films: (1) the melting process is quasi-steady (Yoo and others, 1998; Groulx and Lacroix, 2003); (2) the flow in the melt film remains laminar (Groulx and Lacroix, 2003, 2007); (3) the melt film is very thin compared with the diameter of the thermal head, $\delta \ll R$, and a lubrication theory is valid for describing the melt film (Chen and others, 2008; Schüller and Kowalski, 2017); (4) viscous forces are dominant in the melt film, and $\partial^{2 /} \partial h^{2} \ll \partial^{2 /} \partial s^{2}$ (Chen and others, 1994); (5) the pressure in the melt film is uniform in the $s$-direction (Batchelor, 1967; Kumano and others, 2005b); (6) heat transfer in the melt film is dominated by conduction, and the heat transported through convective flow is negligible (Bahrami and Wang, 1987; Chen and others, 1994); (7) the temperature distribution in the melt film is linear (Groulx and Lacroix, 2003; Schüller and others, 2016); (8) the distribution of water velocity in the $h$-direction is paraboloidal; (9) the buoyancy force is ignored.

\subsection{Mathematical model}

Based on assumptions (1) to (5) above, the governing NavierStokes equation for the melt film is simplified, and the conservation equation of continuity/momentum can be written as follows:

$$
\begin{gathered}
\frac{\partial u}{\partial h}+\frac{\partial v}{\partial s}=0, \\
\mu \frac{\partial^{2} u}{\partial s^{2}}=\frac{\mathrm{d} p}{\mathrm{~d} h} .
\end{gathered}
$$

The energy equation of the water film can also be simplified based on assumptions (1) and (6):

$$
\alpha_{\mathrm{w}} \frac{\partial^{2} T}{\partial s^{2}}=0
$$

where $\alpha_{\mathrm{w}}=k_{\mathrm{w}} /\left(\rho_{\mathrm{w}} c_{\mathrm{w}}\right)$ is the thermal diffusivity of water. At the water-ice interface $\Gamma_{\mathrm{p}}(s=\delta)$, an energy-balance equation or Stefan condition exists, which is

$$
-\left.k_{\mathrm{w}} \frac{\partial T}{\partial s}\right|_{s=\delta}=\rho_{\mathrm{w}} V\left[L_{\mathrm{m}}+c_{\mathrm{w}}\left(T_{\mathrm{m}}-T_{\mathrm{i}}\right)\right] \cos \varphi .
$$

During the drilling process, the axial load acting on the thermal head is always balanced by the pressure built in the water film. The force-balance equation is expressed as follows:

$$
F=\iiint_{\sum_{\mathrm{p}}} p \mathrm{~d} A_{\mathrm{p}}
$$

Boundary conditions are required for the velocity and temperature of the water film to enclose the model. At the working surface of the thermal head $\Gamma_{\mathrm{h}}$, we have a no-slip, zero-inflow condition and a constant power input or constant temperature:

$$
\begin{gathered}
u=v=0 \\
\left.\frac{\partial T}{\partial s}\right|_{s=0}=-\frac{P}{A_{\mathrm{h}} k_{\mathrm{w}}} \quad(\mathrm{PDC}) \\
T=T_{\mathrm{h}}(\mathrm{TDC}) .
\end{gathered}
$$

At the phase interface $\Gamma_{\mathrm{p}}$, we also have a no-slip condition in the $h$-direction, which is

$$
u=0 \text {. }
$$

Considering the density variations owing to the phase change, the velocity component of the water film in the $s$-direction is

$$
v=-\frac{\rho_{\mathrm{i}}}{\rho_{\mathrm{w}}} V \cos \varphi
$$

As mentioned above, the temperature at the phase interface $\Gamma_{\mathrm{p}}$ remains the melting point of ice, and the pressure in the outflow boundary of melt film $\Gamma_{\mathrm{w}}$ equals to hydrostatic water pressure in the borehole:

$$
T=T_{\mathrm{m}}
$$

$$
p=\rho_{\mathrm{w}} g H \text {. }
$$


The governing equation for ice can be expressed using a steady advection-diffusion equation:

$$
\alpha_{\mathrm{i}} \frac{\partial^{2} T}{\partial s^{2}}+V \cos \varphi \frac{\partial T}{\partial s}=0
$$

in which $\alpha_{\mathrm{i}}=k_{\mathrm{i}} /\left(\rho_{\mathrm{i}} c_{\mathrm{i}}\right)$ is the thermal diffusivity of ice. The boundary conditions for Eqn (13) are expressed as follows:

$$
\begin{gathered}
T(s=\delta)=T_{\mathrm{m}}, \\
T(s \rightarrow \infty)=T_{\mathrm{i}} .
\end{gathered}
$$

In the view of the macro-scale power energy balance, the energy input from the thermal head can be divided into two parts. The first part is used to increase the initial temperature of the ice to the melting point temperature and then, transform the solid ice into liquid water, which can be calculated as follows:

$$
P_{\mathrm{E}}=\pi R^{2} V \rho_{\mathrm{i}}\left[L_{\mathrm{m}}+c_{\mathrm{i}}\left(T_{\mathrm{m}}-T_{\mathrm{i}}\right)\right] .
$$

The second part is lost when the melting ice flows out through the small gap between the thermal head and the ice. The lost power can be calculated by integrating the outflow boundary of the water film:

$$
P_{\mathrm{L}}=2 \pi R \rho_{\mathrm{w}} c_{\mathrm{w}} \int_{0}^{\delta} u\left(T-T_{\mathrm{m}}\right) \mathrm{d} s
$$

Assumptions (7) and (8) are adopted to simplify Eqn (17). Therefore, the average temperature in the melt film is expressed as follows:

$$
T_{\mathrm{w}}=\frac{1}{2}\left(T_{\mathrm{h}}+T_{\mathrm{m}}\right)
$$

The integration of the velocity component $u$ in the outflow boundary becomes

$$
\int_{0}^{\delta} u \mathrm{~d} s=\frac{2}{3} u_{\max } \delta
$$

Hence, Eqn (17) is rewritten as follows:

$$
P_{\mathrm{L}}=\frac{2}{3} \pi R \rho_{\mathrm{w}} c_{\mathrm{w}} u_{\max } \delta\left(T_{\mathrm{h}}-T_{\mathrm{m}}\right)
$$

Based on assumption (7) and Eqn (3), the temperature of the thermal head under the PDC is

$$
T_{\mathrm{h}}=\frac{P \delta}{A_{\mathrm{h}} k_{\mathrm{w}}}+T_{\mathrm{m}}
$$

Thus, the lost power becomes

$$
P_{\mathrm{L}}=\frac{2}{3} \pi R \rho_{\mathrm{w}} c_{\mathrm{w}} u_{\max } \frac{P \delta^{2}}{A_{\mathrm{h}} \mathrm{k}_{\mathrm{w}}}
$$

Under TDC, the lost power is represented using Eqn (20). The heat flux at the working surface of the thermal head can be evaluated as follows:

$$
q_{\mathrm{h}}=\left.k_{\mathrm{w}} \frac{\partial T}{\partial s}\right|_{s=0}=\frac{\left(T_{\mathrm{h}}-T_{\mathrm{m}}\right) k_{\mathrm{w}}}{\delta} .
$$

By integrating Eqn (23), the input power under TDC can be calculated as follows:

$$
P=\iint q_{\mathrm{h}} \mathrm{d} A_{\mathrm{h}} .
$$

Regardless of the type of boundary condition used for the working surface of the thermal head, the macro-scale power balance equation is expressed as

$$
P=P_{\mathrm{L}}+P_{\mathrm{E}}
$$

This study mainly focuses on ice-melting process below thermal head. To eliminate the influence of water column in the melted borehole on the drilling process, the pressure in the outflow boundary of melt film can be set as zero and Eqn (12) becomes

$$
p=0 \text {. }
$$

In this situation, the force balance equation (5) should be rewritten as

$$
F^{*}=\iint_{\Sigma_{\mathrm{p}}} p \mathrm{~d} A_{\mathrm{p}}
$$

where $F^{*}$ is the BCF named by Schüller and Kowalski (2019) and can be expressed as:

$$
F^{*}=F-\pi R^{2} \rho_{\mathrm{w}} g H .
$$

In ice drilling engineering, the efficiency of a thermal head is defined, as expressed in Eqn (29), to evaluate the energy efficiency when drilling downward:

$$
\eta=\frac{P_{\mathrm{E}}}{P}
$$

\subsection{Model solution}

An analytical-numerical hybrid method implemented into commercial software, COMSOL Multiphysics 5.3a, was developed to solve the model. As shown in Figure 2, the calculation process involves five steps:

(1) The values of the water-film thickness and ROP were initially assumed. The water-film thickness is in $\mu \mathrm{m}$, and the ROP can be estimated using Eqn (16) if PDC is applied.

(2) The conservation equation of continuity/momentum and force balance equations are solved numerically by coupling a thin-film flow (shell) module and a solid mechanics module in the software. Subsequently, the updated values of the water-film thickness, flow velocity and pressure distribution in the water film can be obtained.

(3) As the updated value of the water-film thickness is known, the energy equation can be solved analytically. Eqn (21) is then used to calculate the temperature of the thermal head (PDC), whereas Eqns (23) and (24) can be used to estimate the input power of the thermal head (TDC). 


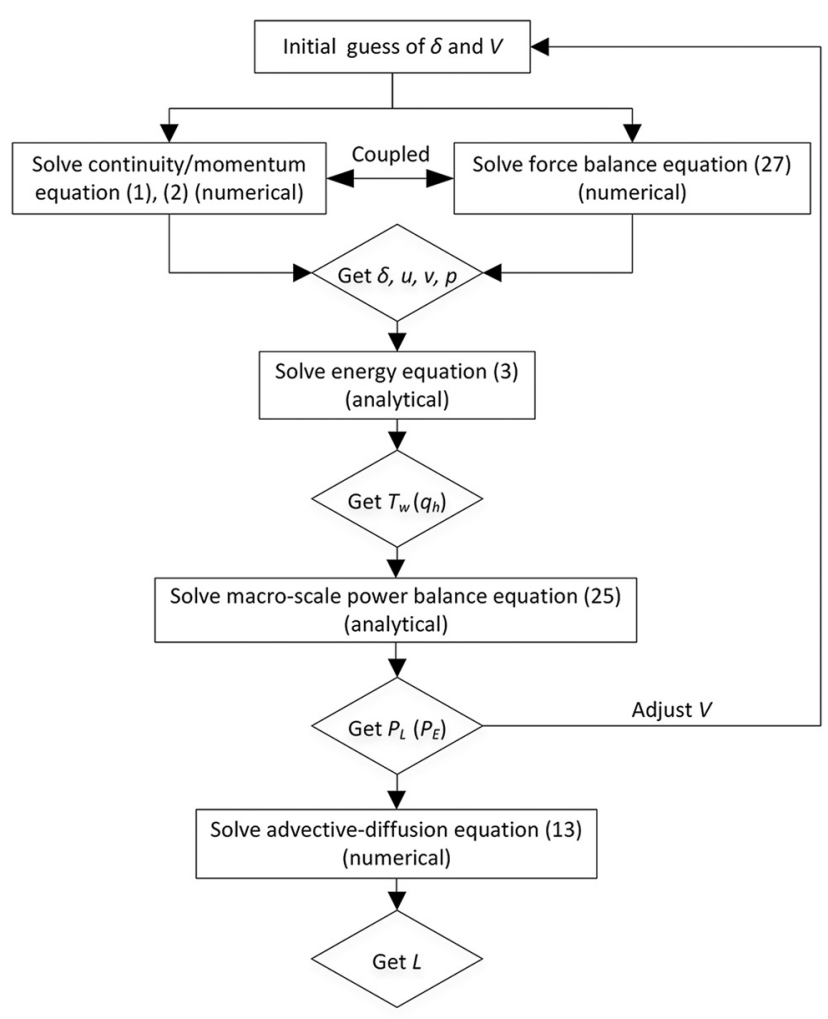

Fig. 2. Flow diagram for calculating the proposed model.

(4) The power loss is computed, and the macro-scale power equation is then evaluated. If the macro-scale power equation is balanced, we can go to the next step. Otherwise, the initial $V$ should be adjusted, and the steps above should be repeated until the equation becomes balanced.

(5) The advection-diffusion equation in ice is solved numerically to observe the temperature distribution in the ice column and to evaluate the range of heat disturbance. In the calculations, the ice is moved at a velocity $V$ with respect to the thermal head.

In steps (2) and (5), the governing equations are solved numerically and a spherical thermal head, which is shown in Figure 3, is used as an example to demonstrate the meshes used in the two steps. In both the meshes, the ice block is divided into two parts: the active ice layer near water-ice interface and the inactive ice layer far from it. The active layer has a smaller mesh size than the inactive layer. The thickness of the active ice layer is chosen to be $20 \mathrm{~mm}$. In step (2), the spherical surface is water film while it is
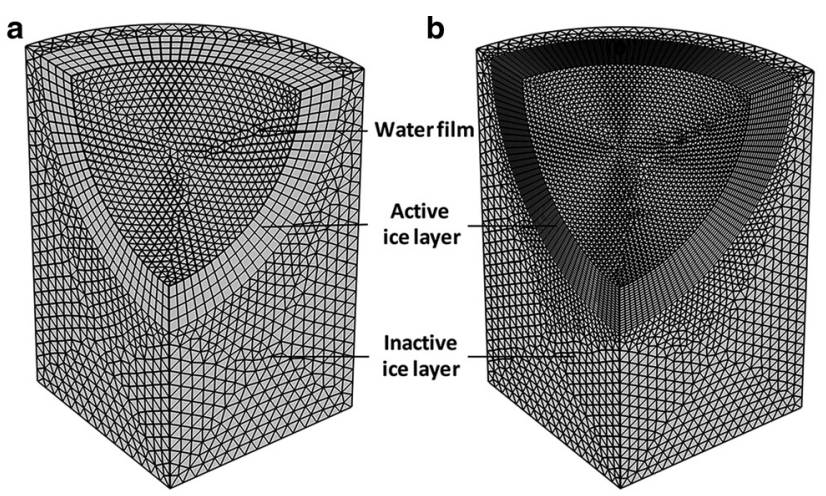

Fig. 3. Examples of the meshes used in the calculation process with COMSOL Multiphysics 5.3a: (a) step (2); and (b) step (5) ice in step (5). To calculate the accurate distance of heat disturbance, the mesh in step (5) is recalculated to be smaller than the mesh used in step (2), especially in the active ice layer. In Figure $3 \mathrm{a}$, the active ice layer contains 5220 pentagonal prism mesh elements while the inactive ice layer contains 55174 tetrahedron mesh elements. With finer mesh, the active ice layer in Figure $3 \mathrm{~b}$ contains 58788 pentagonal prism mesh elements and the inactive ice layer contains 105347 tetrahedron mesh elements. The software COMSOL Multiphysics 5.3a was run on a computer with Windows 10 platform. The computer has a CPU of Intel (R) Core (TM) i5-3230M and its RAM is $8 \mathrm{~GB}$. Depending on the shape of the thermal head, the calculation time for step (2) varies from 10 to $15 \mathrm{~min}$ while the calculation time for step (5) is in the range of $3-6 \mathrm{~min}$. The total time consumed by all five steps is $\sim 40-60 \mathrm{~min}$.

In our calculations, the physical properties of water and ice are assumed to be constant, as listed in Table 1 .

\subsection{Models comparison}

To validate our model, our calculating results are compared with the analytical solutions given by Aamot (1967) and Schüller and Kowalski (2019). The initial conditions are taken from Schüller and Kowalski (2019) where a cylindrical thermal head with a radius of $6 \mathrm{~cm}$ is used to drill ice in the vicinity of Enceladus' tiger stripes. During drilling, the power of the thermal head changes from 1000 to $5000 \mathrm{~W}$ while BCF is $0.1,10$ and $1000 \mathrm{~N}$.

Aamot (1967) ignored the power loss, so the ROP increases linearly with input power and the BCF had no influence on it (Fig. 4a). The maximum ROP for a predetermined power input calculated by Aamot's method is higher than our estimates. The ROP calculated in our model is a little higher than that in Schüller and Kowalski (2019) except for the case where the BCF is $0.1 \mathrm{~N}$. In the case of $0.1 \mathrm{~N}$, the ROP starts to become lower than the results calculated by Schüller and Kowalski (2019) when power is more than $2500 \mathrm{~W}$. Generally, the discrepancy of ROP becomes bigger with increasing power. The maximum difference in ROP is $8 \%$ when $\mathrm{BCF}$ is $0.1 \mathrm{~N}$ while it is only $2 \%$ if the BCF increases to $10 \mathrm{~N}$ or $1000 \mathrm{~N}$.

The difference in temperature of the thermal head is shown in Figure $4 \mathrm{~b}$. Similar to ROP, the temperature of the thermal head in our model is also higher than the value calculated by Schüller and Kowalski (2019), but both models have the same trend in the temperature of thermal head. With the decrease of BCF, the discrepancy in the temperature of thermal head increases from 1.2 to $3.7 \%$. This indicates a good agreement of our model with the analytical solution. Schüller and Kowalski (2019) assumed that the heat transported by convective flow affects temperature distribution and a quadratic polynomial Ansatz for the temperature field in $s$ direction was taken. This is the main reason which leads to the difference between our results and the analytical solution.

Table 1. Physical properties of water and ice

\begin{tabular}{lll}
\hline Properties & Value & Unit \\
\hline$\rho_{\mathrm{w}}$ & 1000 & $\mathrm{~kg} \mathrm{~m}^{-3}$ \\
$c_{\mathrm{w}}$ & 4218 & $\mathrm{~J} \mathrm{~kg}^{-1} \mathrm{~K}^{-1}$ \\
$k_{\mathrm{w}}$ & 0.6 & $\mathrm{~W} \mathrm{~m}^{-1} \mathrm{~K}^{-1}$ \\
$\mu$ & 0.0013 & $\mathrm{~Pa} \mathrm{~s}^{-1}$ \\
$L_{\mathrm{m}}$ & 334000 & $\mathrm{~J} \mathrm{~kg}^{-1}$ \\
$T_{\mathrm{m}}$ & 273.15 & $\mathrm{~K}$ \\
$\rho_{\mathrm{i}}$ & 917 & $\mathrm{~kg} \mathrm{~m}^{-3}$ \\
$c_{\mathrm{i}}$ & 2050 & $\mathrm{~J} \mathrm{~kg}^{-1} \mathrm{~K}^{-1}$ \\
$k_{\mathrm{i}}$ & 2.38 & $\mathrm{~W} \mathrm{~m}^{-1} \mathrm{~K}^{-1}$ \\
\hline
\end{tabular}



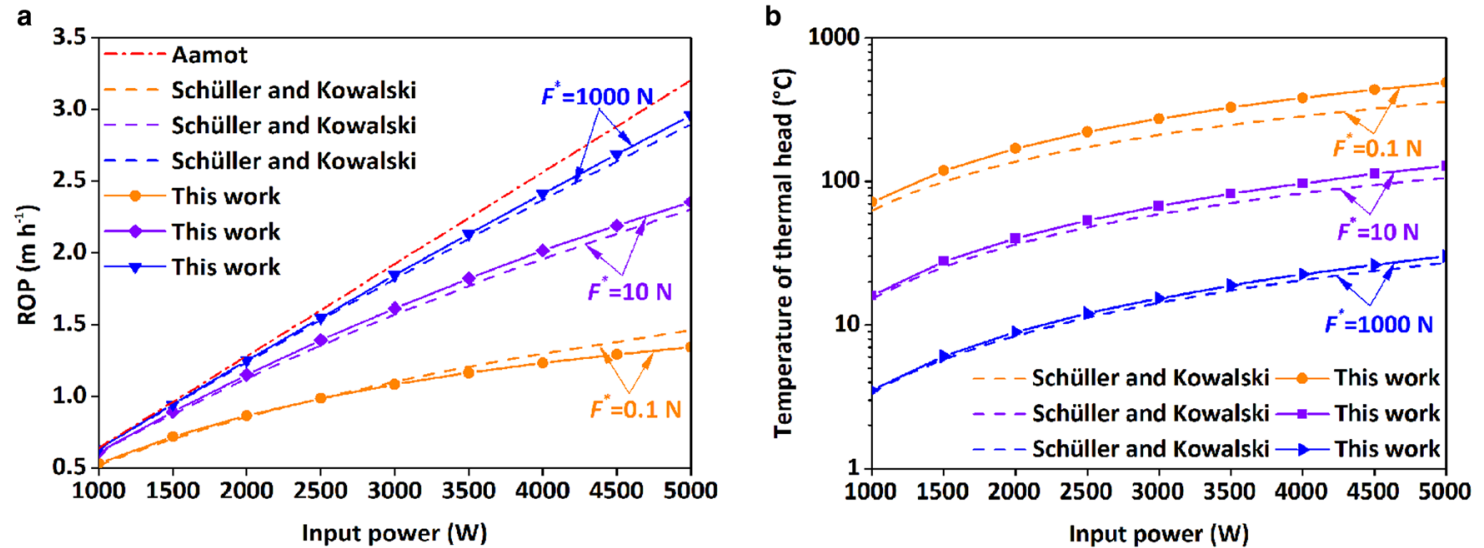

Fig. 4. Model validation by comparing with the analytical solutions given by Aamot (1967) and Schüller and Kowalski (2019): (a) ROP; (b) temperature of thermal head.

\section{Results and discussion}

\subsection{Effect of thermal head shape}

Four thermal heads with cylindrical, spherical, paraboloidal and conical shapes, respectively (Fig. 5), were applied to investigate how the shape of the thermal head influences the thermal drilling process. The radius of each of the thermal heads was $6 \mathrm{~cm}$. The area of the working surface for the spherical, paraboloidal and conical thermal head was the same, whereas that for the cylindrical thermal head was one-half of the others. This difference indicates a double heat flux for the cylindrical thermal head under PDC. In the calculations, only a quarter of the thermal heads were used owing to their axisymmetric property.

\subsubsection{PDC}

All the thermal heads were used to drill into $-30^{\circ} \mathrm{C}$ ice with a power of $5000 \mathrm{~W}$ and a BCF of $1000 \mathrm{~N}$. The distribution of the film thickness is shown in Figure 6a. The film thickness is even for the cylindrical and conical thermal heads. The paraboloidal thermal head had the highest difference in film thickness, and the film thickness decreased gradually from the center of the working surface to the outer edge. At the center of its working surface, the film thickness was close to $126 \mu \mathrm{m}$ The cylindrical thermal head had the smallest film thickness.

Figure $6 \mathrm{~b}$ shows the pressure distribution in the water film. From the center of the working surface to the outer edge, the water pressure under the cylindrical thermal head varied from 175 to $0 \mathrm{kPa}$. For the other thermal heads, the change in pressure was not as significant as that of the cylindrical thermal head. The temperature values of the cylindrical and conical thermal heads were comparatively more uniform, and the paraboloidal thermal head had the highest temperature difference (Fig. 6c). With the input power of $5000 \mathrm{~W}$, the working surface of the paraboloidal thermal head reached $46.4^{\circ} \mathrm{C}$ at its center. For the spherical and paraboloidal thermal heads, the temperature decreased gradually from the center of the working surface to its outer edge.

In Figure 6d, the maximum tangential velocity of the melt film $u_{\max }$ is shown, and the flow direction is marked using red arrows. Irrespective of the thermal head type, the flow velocity increased from the center of the working surface to its outer edge, and the velocity at the center remained zero. At the outflow boundary of the melt film, the order of the flow velocity was as follows: cylinder $>$ sphere $>$ paraboloid $>$ cone. The maximum flow velocity at the outflow boundary of the water film was $0.74 \mathrm{~m} \mathrm{~s}^{-1}$, which means that the water was squeezed out as jetting.

The temperature distribution in the active ice layer is shown in Figure 6e. The range of the heat disturbance is narrow, and the non-heat-disturbed isothermal virtual surface had almost the same profile as the thermal head. For the spherical thermal head and the paraboloidal thermal head, the temperature gradient became smaller with increasing distance from the center of working surfaces.

As shown in Figure 7, the order of ROP for the thermal heads at the same power is as follows: sphere $>$ paraboloid $>$ cone $>$ cylinder. However, the difference in ROP was minimal; for example, the spherical thermal head could only drill 3.6\% faster than the cylindrical thermal head. The difference in ROP between the paraboloidal and conical thermal heads was even smaller, namely $<0.7 \%$. It can also be observed that a higher ROP always indicates a lower power loss fraction, which is the ratio of lost power to input power. Correspondingly, the thermal head with higher ROP has higher efficiency. The conical thermal head had the smallest heat disturbance range, whereas the cylindrical thermal head had the broadest range. From the results reported above, a thermal head with a spherical shape should be used for drilling under PDCs.
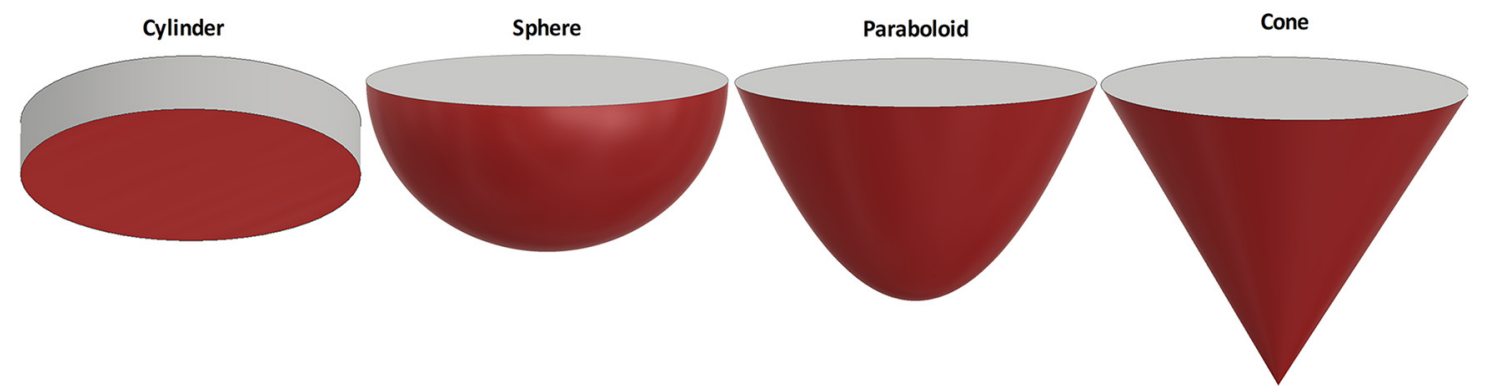

Fig. 5. Four thermal heads with different shapes (working surfaces of the thermal heads are marked by red). 


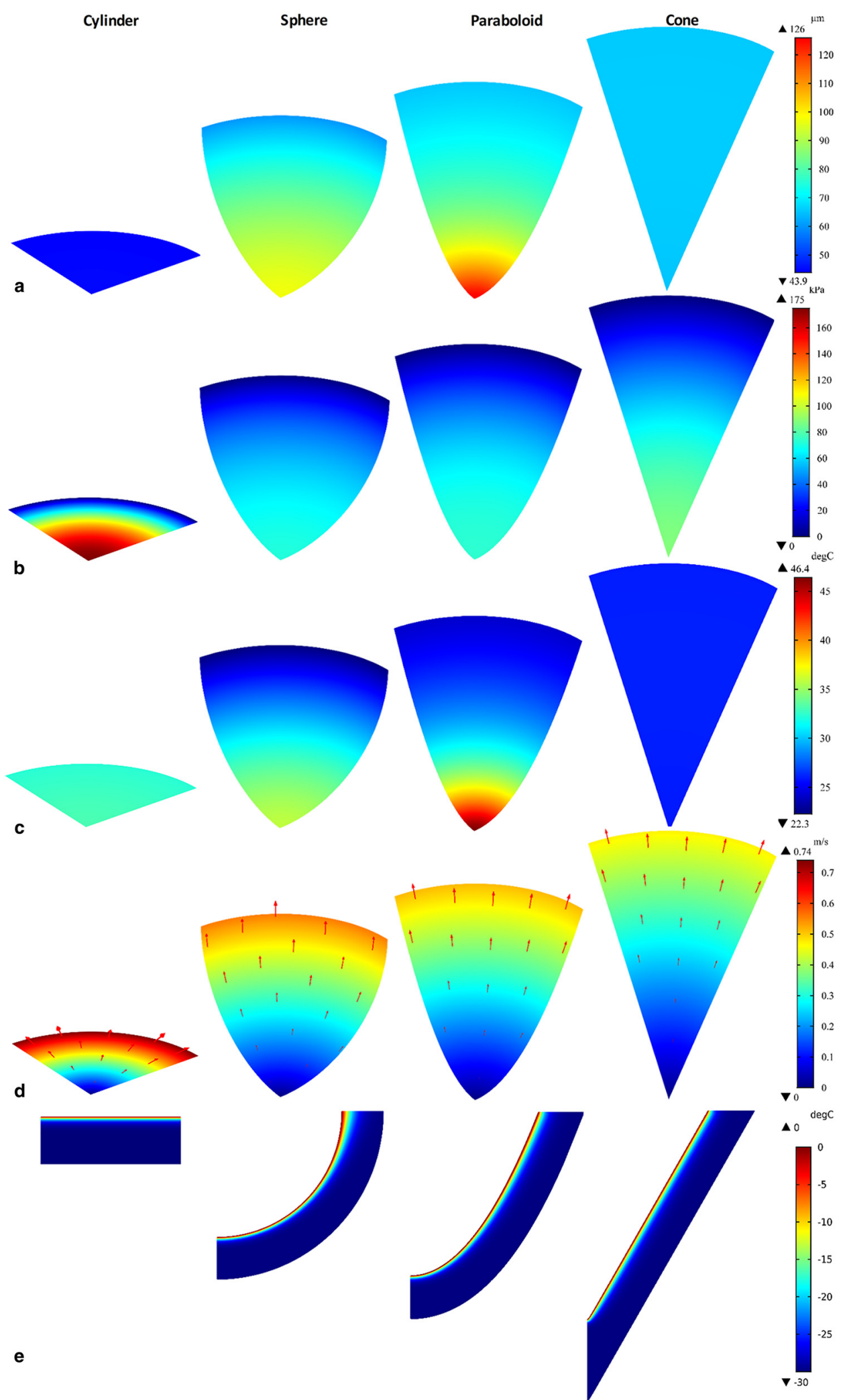

Fig. 6. Influence of thermal head shape on (a) film thickness; (b) pressure in melt film; (c) temperature of thermal head; (d) flow velocity of melt film; (e) temperature distribution in the active ice layer under PDC.

For an electrically heated thermal head, its shape usually influences the distribution of heaters, which consequently influences the heat distribution on the thermal head. Thus, in designing a thermal head, the fitting shape of the thermal head can only be determined by considering both the shape effect and the heater distribution.

\subsubsection{TDC}

Ice at $-30^{\circ} \mathrm{C}$ was modeled for drilling using the four thermal heads at $20^{\circ} \mathrm{C}$ to evaluate the shape effect of the thermal head under TDC. The BCF had a constant value of $1000 \mathrm{~N}$ throughout the drilling process. Similar to the case under PDC, the cylindrical and conical thermal heads had a uniform film thickness, and the cylindrical 


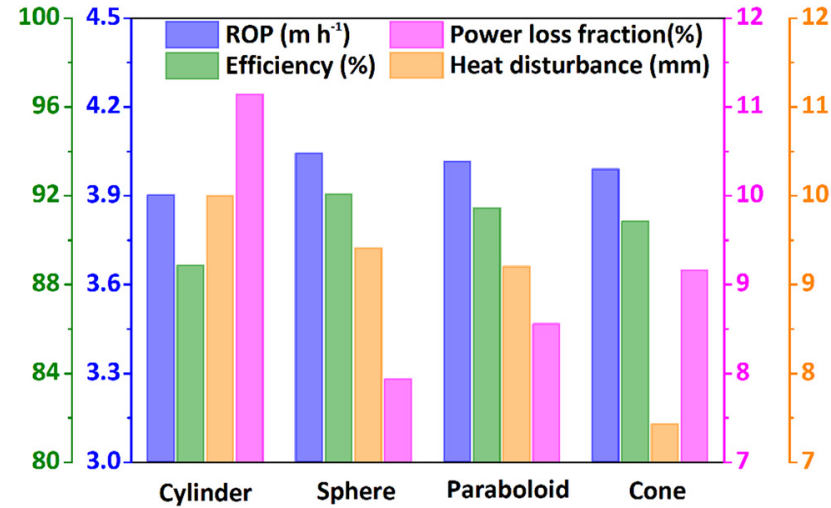

Fig. 7. Influence of thermal head shape on ROP, efficiency of thermal head, power loss fraction and distance of heat disturbance under PDC.

thermal head had the smallest film thickness (Fig. 8a). The spherical thermal head had a higher difference in film thickness than the paraboloidal thermal head, which was different from the situation under the PDC. The largest film thickness existed at the center of the working surface in the spherical thermal head.

As shown in Figure $8 \mathrm{~b}$, the pressure distribution under TDC was entirely similar to that under PDC. Figure $9 c$ displays the heat flux of the thermal head under TDC. The heat flux in the cylindrical thermal head was more uniform and significantly higher than that of the other thermal heads. The spherical thermal head had the most significant difference in terms of heat flux, and the value increased from 11.6 to $23.8 \mathrm{~W} \mathrm{~cm}^{-2}$. The heat flux of the conical thermal head was also evenly distributed and was $\sim 18 \mathrm{~W} \mathrm{~cm}^{-2}$.

As depicted in Figure 8d, the distribution of the maximum tangential flow velocity under TDC was similar to that of PDC. The flow velocity increased from zero at the center of the working surface to its maximum value at the outflow boundary, and the maximum velocity was obtained for the cylindrical thermal head. Figure $8 \mathrm{e}$ illustrates the temperature distribution in the active ice layer. By comparison, it can be seen that there is an insignificant difference in the ice temperature distribution, regardless of the heat condition type applied to the thermal heads.

When a constant temperature of $20^{\circ} \mathrm{C}$ was applied to the working surface of the thermal heads, the order of the penetration rate was as follows: cone $>$ paraboloid $>$ sphere $>$ cylinder (Fig. 9). The conical thermal head could melt ice at a velocity of $3.33 \mathrm{~m} \mathrm{~h}^{-1}$, whereas the cylindrical thermal head could only drill at a penetration rate as high as $2.79 \mathrm{~m} \mathrm{~h}^{-1}$. The order of the calculated input power is the same as the penetration rate, which suggests that a higher ROP requires a higher input power. For all the thermal heads, the efficiency was $92.8 \%$. In contrast to the penetration rate, the heat disturbance distance for the cylindrical thermal head was the longest, whereas that of the conical thermal head was the shortest.

\subsection{Effect of cone angle}

Cone is the most widely used shape for thermal heads. To study how the cone angle affects the thermal drilling process, the conical thermal heads with cone angles varying from 20 to $180^{\circ}$ were investigated under both PDC and TDC. All the conical thermal heads have a radius of $6 \mathrm{~cm}$. With increasing cone angle, the working surface area of the thermal heads gradually decreases. The decreasing rate is high at the beginning, and then, it becomes lower.

\subsubsection{PDC}

The thermal heads with different cone angles were modeled with input power of $5000 \mathrm{~W}, \mathrm{BCF}$ of $1000 \mathrm{~N}$ and ice temperature of $-30^{\circ} \mathrm{C}$. The thickness, pressure and flow velocity of water film increase with the increase of cone angle, while the temperature of thermal head decreases (Fig. 10a). The changing rate of the parameters has the same trend as the working surface area of the thermal heads. With the increase of cone angle, the differences in the water-film thickness and thermal head temperature become smaller. For example, the difference in film thickness decreases from 20 to $1 \mu \mathrm{m}$ when cone angle increases from 20 to $180^{\circ}$. As shown in Figure 10b, the penetration rate and efficiency of conical thermal head decrease with cone angle. However, it should be mentioned that the decreases in ROP and efficiency are quite small. For example, the ROP and efficiency only decrease 0.189 $\mathrm{m} \mathrm{h}^{-1}$ and $4.4 \%$, respectively, when cone angle increases from 20 to $180^{\circ}$. The power loss increases with the increase of cone angle, while the range of heat disturbance in ice first decreases quickly and then increases a little. When cone angle is $60^{\circ}$, the thermal head has the minimum heat disturbance on ice.

\subsubsection{TDC}

The working surfaces of the conical thermal heads with different cone angles were assumed to be $20^{\circ} \mathrm{C}$ to investigate the effects of cone angle under TDC. In thermal modeling, BCF on the thermal heads is $1000 \mathrm{~N}$ and ice temperature remains $-30^{\circ} \mathrm{C}$. Under TDC, the variation of the parameters shown in Figure 11a, such as thickness, pressure and flow velocity of the melt film, has the same trends as the case under PDC. The heat flux of thermal head increases with the increase in cone angle, while the difference in heat flux decreases. As shown in Figure 11b, the ROP decreases quickly when cone angle is small. When cone angle becomes bigger, the reduction rate of ROP becomes smaller. Correspondingly, the input power also decreases with the increase of cone angle. Cone angle has no influence on thermal head efficiency. The change of heat disturbance distance with cone angle under TDC is the same as the case under PDC.

Generally, the decrease in cone angle can lead to the increase of ROP, but the increase is quite small. In designing a conical thermal head, it is suggested that the cone angle, material consumption, heater distribution and other factors should be considered together. It is not worthy to pursue a small cone angle for just a little improvement in ROP by sacrificing other factors.

\subsection{Effect of buoyancy corrected force}

Compared with other thermal heads, the calculation time for the cylindrical thermal head was shorter based on the output using COMSOL Multiphysics 5.3a. Hence, in the following sections, only the cylindrical thermal head is reported in analyzing the effects of the BCF, thermal head power (or temperature) and ice temperature.

\subsubsection{PDC}

The cylindrical thermal head with a power of $5000 \mathrm{~W}$ was modeled for drilling ice at $-30^{\circ} \mathrm{C}$, and the $\mathrm{BCF}$ varied from 1 to 10000 $\mathrm{N}$. As shown in Figure 12a, the maximum pressure and flow velocity of the water film increased with BCF, while the film thickness and thermal head temperature decreased. With the increase in BCF, the differences in the water-film thickness and thermal head temperature, respectively, become higher. For example, the thermal head temperature was uniformly distributed when the BCF was $<1000 \mathrm{~N}$, but the temperature difference increased to $6.3^{\circ} \mathrm{C}$ when the $\mathrm{BCF}$ reached $10000 \mathrm{~N}$. The higher the $\mathrm{BCF}$, the faster the penetration rate (Fig. 12b). However, it should be mentioned that the rate of increase in ROP significantly reduces with the increase in the BCF. For example, ROP increased $1.32 \mathrm{~m} \mathrm{~h}^{-1}$ from 1 to $100 \mathrm{~N}$, whereas it only increased $0.26 \mathrm{~m} \mathrm{~h}^{-1}$ from 1000 to $10000 \mathrm{~N}$. The efficiency of the thermal head showed 


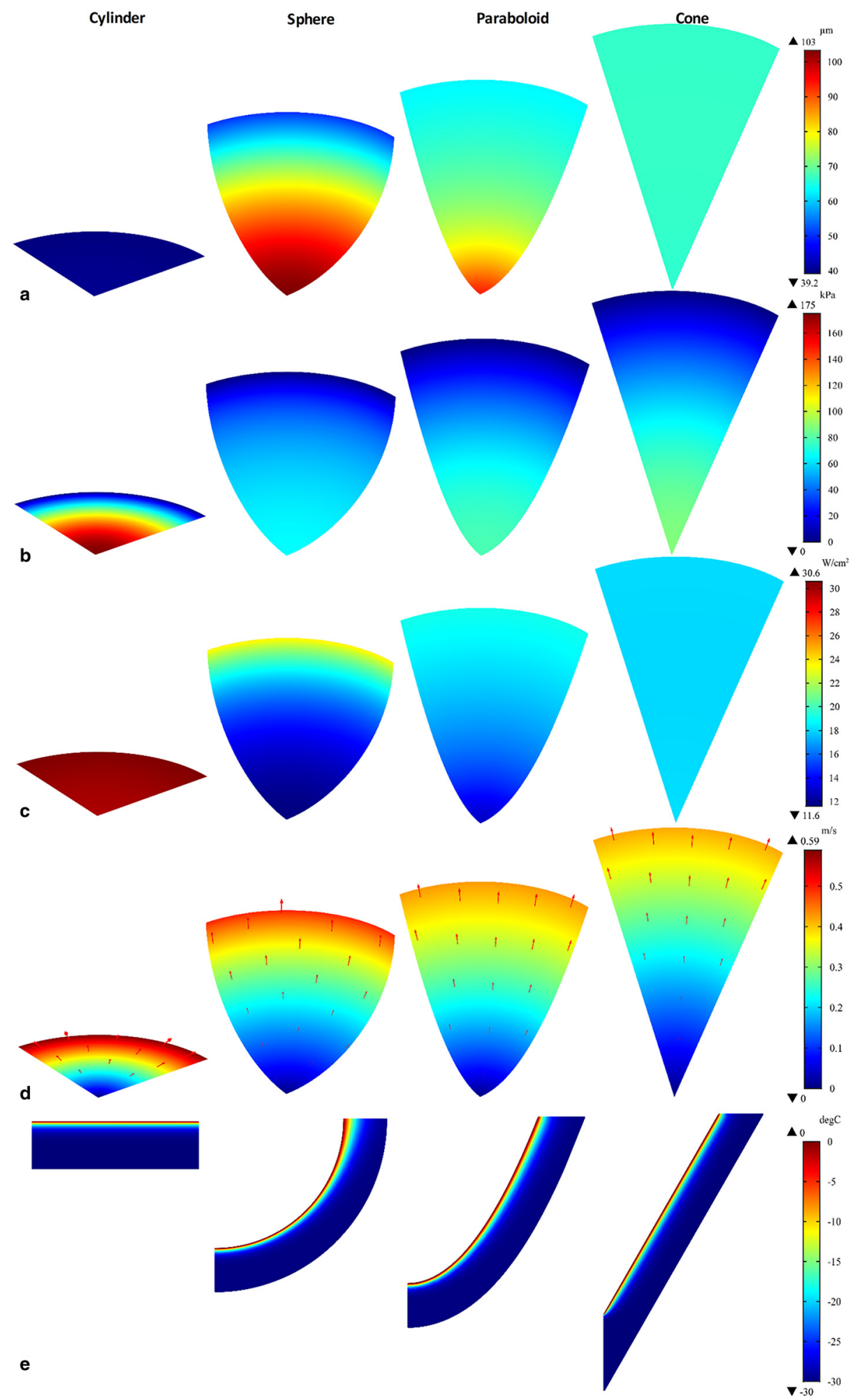

Fig. 8. Influence of thermal-head shape on (a) film thickness; (b) pressure in melt film; (c) heat flux of thermal head; (d) flow velocity of melt film; (e) temperature distribution in the active ice layer under TDC.

a similar trend as the ROP because the power loss decreases as the $\mathrm{BCF}$ increases. The range of the heat disturbance decreased gradually with the increase in BCF. This trend occurred because the cylindrical thermal head drilled faster with increased BCF, and there was no enough time to warm up the surrounding ice.

\subsubsection{TDC}

The modeled cylindrical thermal head was heated at $20^{\circ} \mathrm{C}$ to determine the effect of the BCF under TDC. Other working conditions were the same as those in the previous section. As depicted in Figure 13a, the water-film thickness decreased as the BCF increased. The pressure and flow velocity in the water film increased with BCF. Similar to PDC, the difference in the film thickness increased with BCF. Correspondingly, the difference in heat flux also increased. For example, when the BCF was $10000 \mathrm{~N}$, the maximum heat flux on the working surface of the cylindrical thermal head could be $18.7 \mathrm{~W} \mathrm{~cm}^{-2}$ higher than the minimum value of the heat flux. Under TDC, the heat flux of the thermal head increased with 


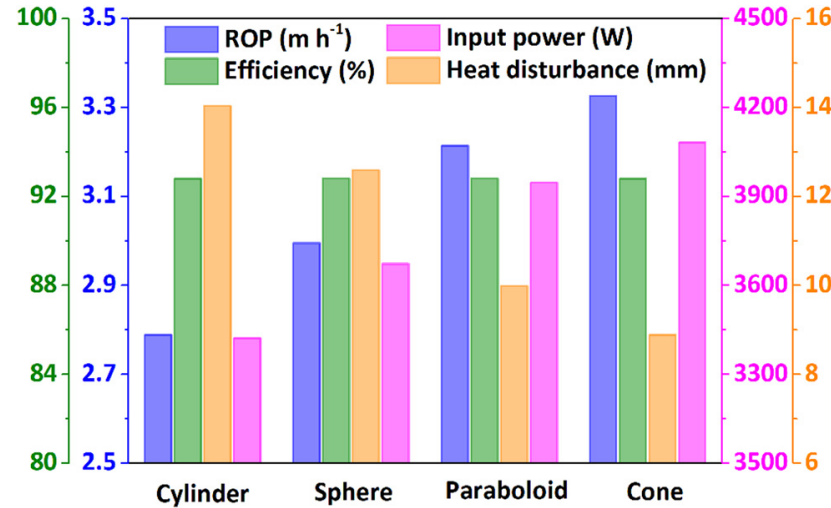

Fig. 9. Influence of thermal head shape on ROP, efficiency of thermal head, input power and distance of heat disturbance under TDC.

BCF. Consequently, the power input on the thermal head and the ROP also increased (Fig. 13b). The BCF did not influence the efficiency of the thermal head under TDC, and the efficiency was maintained at $92.8 \%$. Just as in the previous case for PDC, the heat disturbance distance decreased with the increase in BCF.

Generally, the ROP of a thermal head increases with BCF, which is provided by the weight of the hot-point drill. Therefore, it is better to add a dead weight on a light hot-point drill to increase the axial load acting on the thermal head. For a heavy hot-point drill, its weight in water is usually enough to achieve a high ROP, and the addition of an extra dead weight only increases the ROP slightly and makes the hot-point drill complex. It should be noted that in practice, adding a very high axial load on the thermal head may tilt the hot-point drill.

\subsection{Effect of power (or temperature)}

\subsubsection{PDC}

The cylindrical thermal head with power ranging from 1000 to $5000 \mathrm{~W}$ was used to analyze the effect of power on the drilling process. During the drilling process, the ice temperature was assumed to be $-30^{\circ} \mathrm{C}$, and a constant BCF of $200 \mathrm{~N}$ acted on the thermal head. The results are presented in Figure 14a. The thickness and the flow velocity of the water film increased with the power. It is worth noting that the temperature of the thermal head increased linearly with input power. Both differences in the thermal head temperature and film thickness remained the same when the input power increased. The maximum pressure in the water film did not vary with the input power. As depicted in Figure 14b, the ROP continued to increase as the input power increased. This trend occurred because the increasing quantity of input power was significantly higher than that of heat loss. As an example, when input power increased from 1000 to $5000 \mathrm{~W}$, the power loss only increased from 25 to $870 \mathrm{~W}$. As a result, the efficiency of the thermal head decreased almost linearly from $97.5 \%$ at $1000 \mathrm{~W}$ to $82.6 \%$ at $5000 \mathrm{~W}$. The distance of the heat disturbance initially decreased rapidly and then slowly.
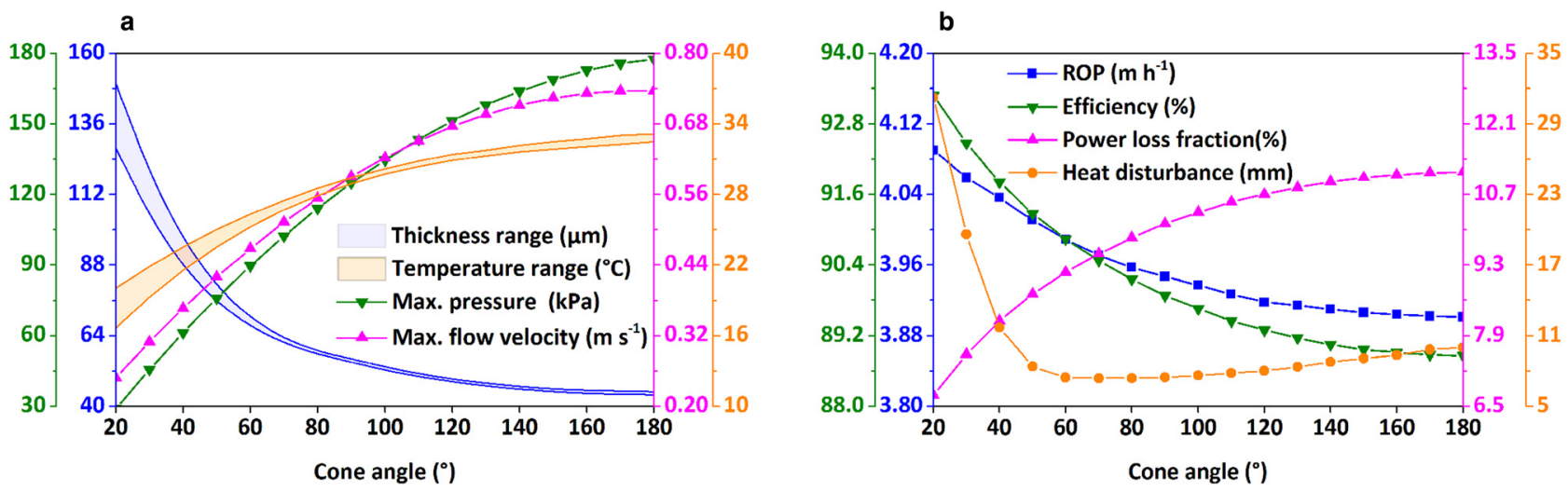

Fig. 10. Influence of cone angle on (a) film thickness, temperature of thermal head, maximum pressure and flow velocity in melt film; (b) ROP, efficiency of thermal head, power loss fraction and distance of heat disturbance under PDC.
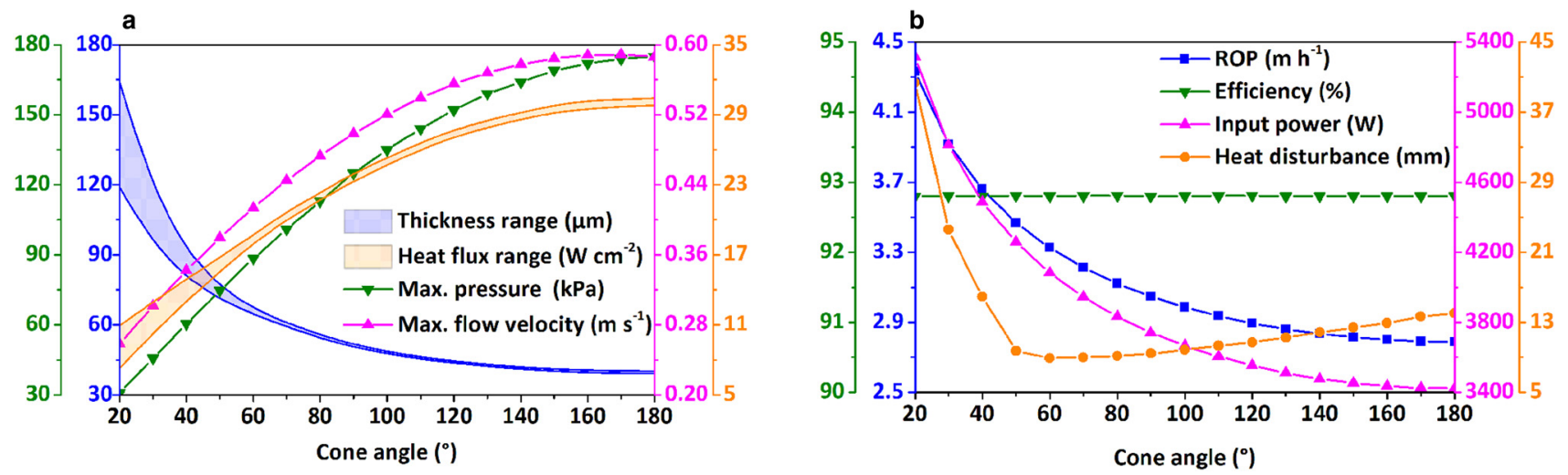

Fig. 11. Influence of cone angle on (a) film thickness, heat flux of thermal head, maximum pressure and flow velocity in melt film; (b) ROP, efficiency of thermal head, input power and distance of heat disturbance under TDC. 

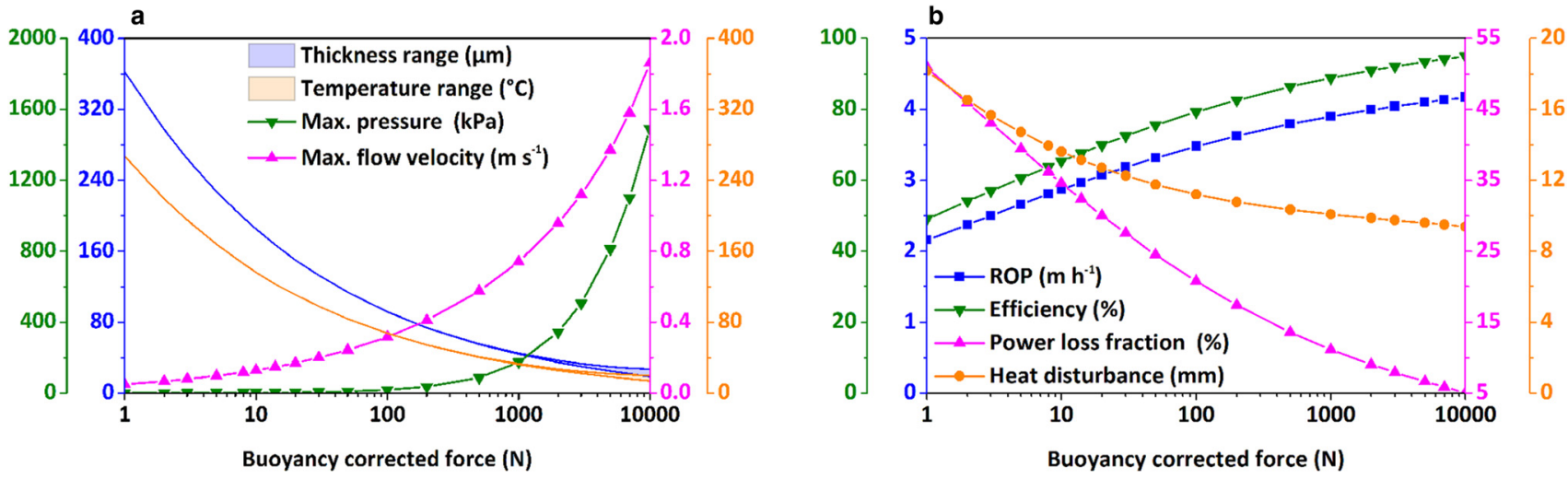

Fig. 12. Influence of buoyancy corrected force on (a) film thickness, temperature of thermal head, maximum pressure and flow velocity in melt film; (b) ROP, efficiency of thermal head, power loss fraction and distance of heat disturbance under PDC.
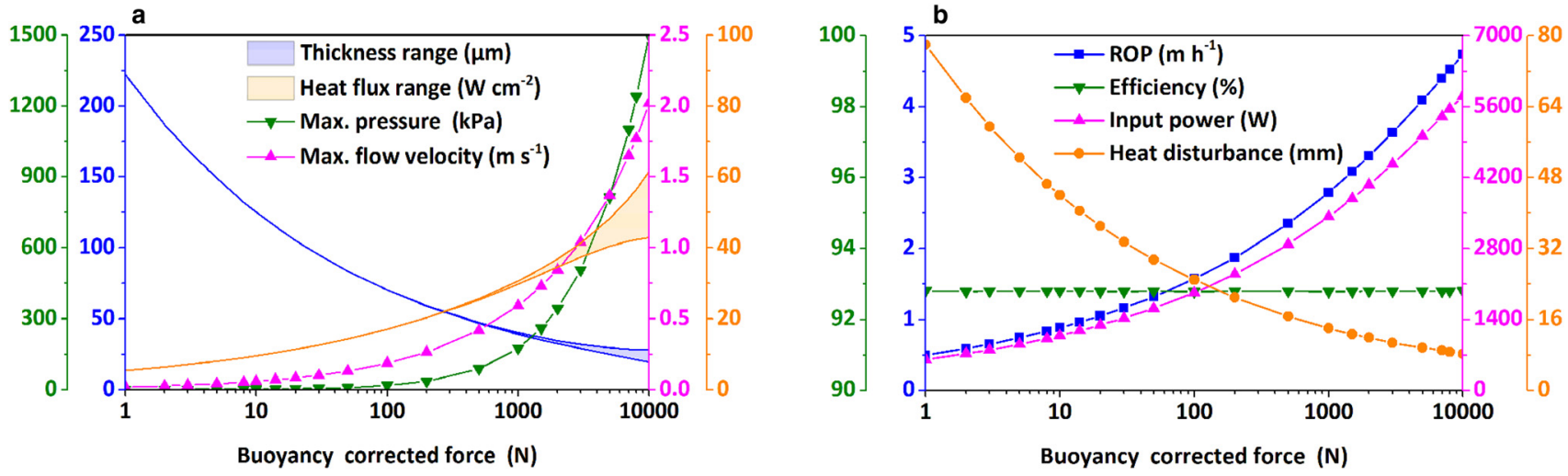

Fig. 13. Influence of buoyancy corrected force on (a) film thickness, heat flux of thermal head, maximum pressure and flow velocity in melt film; (b) ROP, efficiency of thermal head, input power and distance of heat disturbance under TDC.
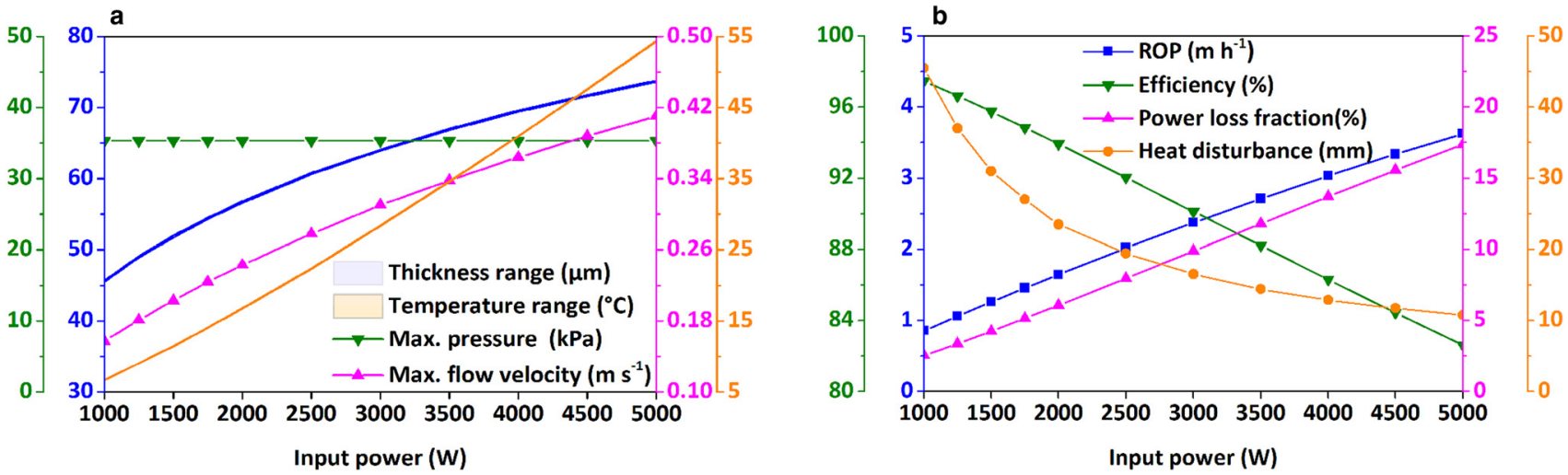

Fig. 14. Influence of power on (a) film thickness, temperature of thermal head, maximum pressure and flow velocity in melt film; (b) ROP, efficiency of thermal head, power loss fraction and distance of heat disturbance under PDC.

\subsubsection{TDC}

The temperature of the cylindrical thermal head was assumed to change from 5 to $40^{\circ} \mathrm{C}$ to evaluate the effect of the thermal head temperature on the drilling process. Similar to the effect of the input power, the maximum flow velocity and water-film thickness increased with thermal head temperature (Fig. 15a). The heat flux of the thermal head increased almost linearly with the temperature, which means that a higher input power is required to obtain a higher temperature on the working surface of the thermal head. The temperature of the thermal head did not influence the pressure in the water film. As shown in Figure 15b, the ROP increases with the thermal head temperature. Similarly, the input power also increased. However, the efficiency of the thermal head decreased from $98.1 \%$ at $5^{\circ} \mathrm{C}$ to $86.6 \%$ at $40^{\circ} \mathrm{C}$. As previously highlighted, a higher ROP reduces the heat disturbance distance; therefore, the range of the heat disturbance under TDC decreased with the increased thermal head temperature.

\subsection{Effect of ice temperature}

\subsubsection{PDC}

We assume that the cylindrical thermal head had an input power of $5000 \mathrm{~W}$ and a BCF of $200 \mathrm{~N}$ to study the effect of ice temperature on the drilling process under PDC. The ice temperature 

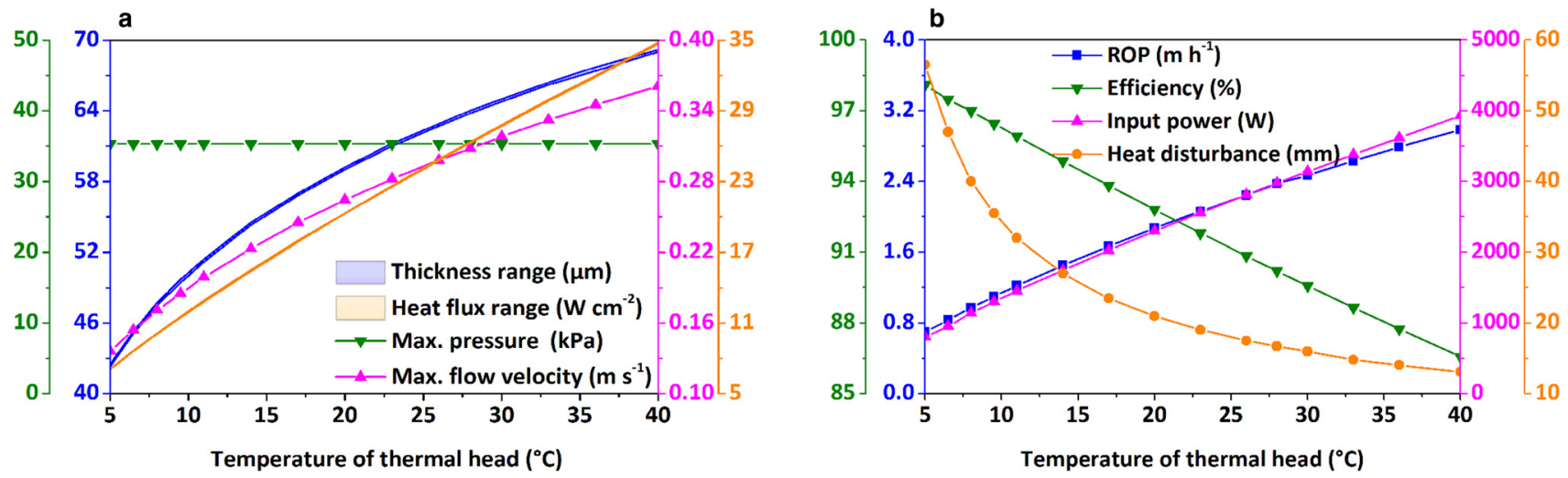

Fig. 15. Influence of temperature on (a) film thickness, heat flux of thermal head, maximum pressure and flow velocity in melt film; (b) ROP, efficiency of thermal head, input power and distance of heat disturbance under TDC.
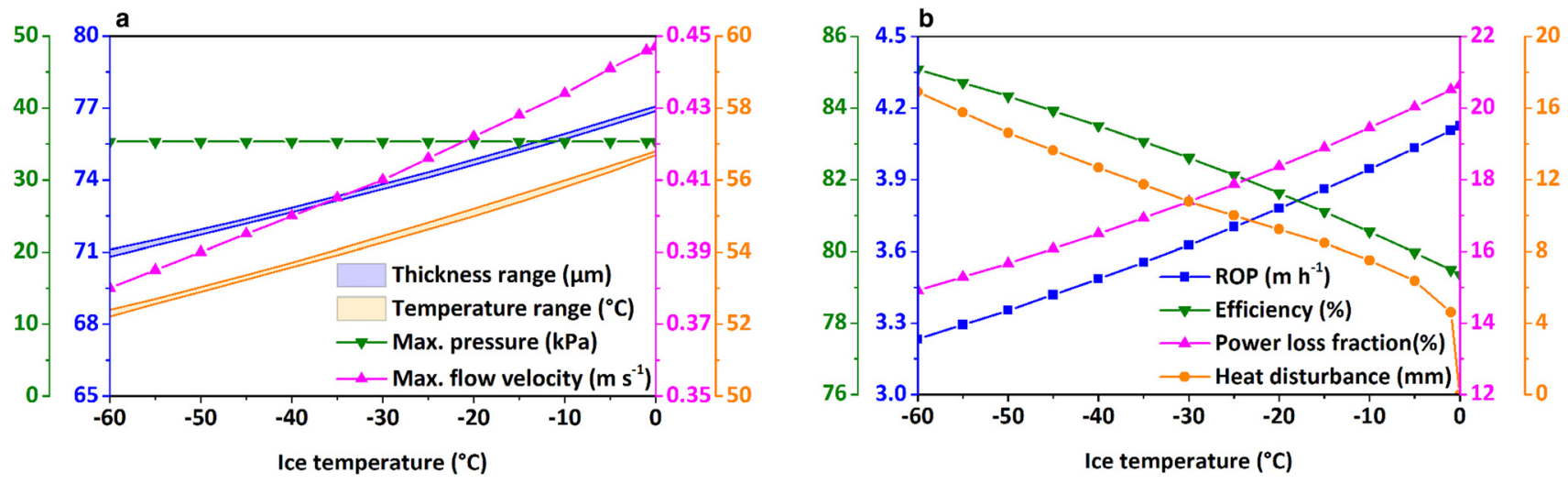

Fig. 16. Influence of ice temperature on (a) film thickness, temperature of thermal head, maximum pressure and flow velocity in melt film; (b) ROP, efficiency of thermal head, power loss fraction and distance of heat disturbance under PDC.
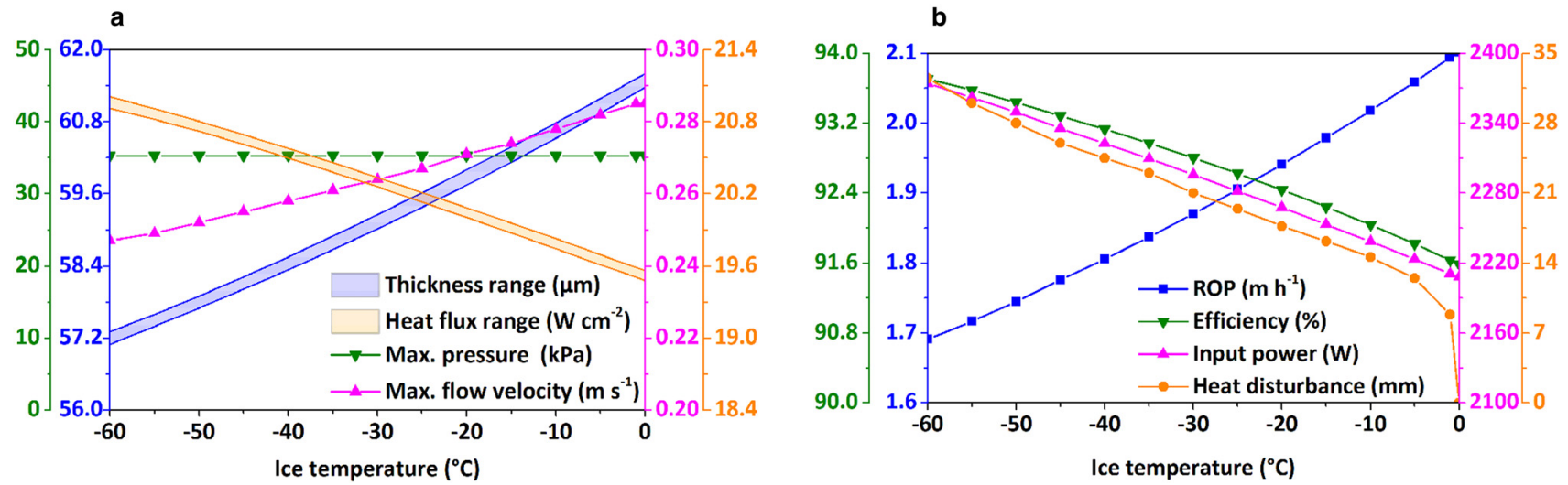

Fig. 17. Influence of ice temperature on (a) film thickness, heat flux of thermal head, maximum pressure and flow velocity in melt film; (b) ROP, efficiency of thermal head, input power and distance of heat disturbance under TDC.

varied from -60 to $0^{\circ} \mathrm{C}$. All the parameters displayed in Figure 16a increased with the ice temperature, except for the pressure in the water film, which remained constant. Combined with the discussion above, we suggest that only the thermal head shape and the BCF influence the pressure distribution in the water film. Similar to the effect of input power, the differences in water-film thickness and thermal head temperature did not change with ice temperature.

The variation of the penetration rate is shown in Figure 16b, and the ROP increases with ice temperature. However, the increase in ROP caused by the ice temperature was smaller than that caused by the BCF and input power. For instance, the maximum increase in ROP caused by the ice temperature was only $0.89 \mathrm{~m} \mathrm{~h}^{-1}$, whereas the value increased to 2.01 and $2.77 \mathrm{~m} \mathrm{~h}^{-1}$ for BCF and input power, respectively. The power loss fraction also increased with ice temperature, and consequently, the efficiency of the thermal head decreased. When ice temperature was lower than $-5^{\circ} \mathrm{C}$, the heat disturbance distance decreased gradually. However, when the ice temperature was above $-5^{\circ} \mathrm{C}$, it decreased rapidly. 


\subsubsection{TDC}

To evaluate the effect of ice temperature under TDC, the drilling condition was set to be the same conditions as under PDC, except that the working surface of the cylindrical thermal head was heated by applying a constant temperature of $20^{\circ} \mathrm{C}$. As shown in Figure 17a, both the thickness and maximum flow velocity of the water film increased when the ice temperature increased from -60 to $0^{\circ} \mathrm{C}$. As ice temperature increased, the heat flux on the thermal head decreased, while the pressure in the water film remained constant. Figure $17 \mathrm{~b}$ shows the variation of the ROP, thermal head efficiency, input power and heat disturbance distance with ice temperature. In Figure 17b, only the ROP increases with increased ice temperature. Consistent with the variation in heat flux, the input power of the thermal head decreased as ice temperature increased. This result means that less power is required to maintain the working surface of the cylindrical thermal head at $20^{\circ} \mathrm{C}$ when ice becomes warmer. For the heat disturbance distance, the variation under TDC was similar to the case under PDC.

Under both PDC and TDC, the ROP always increased with ice temperature. In the Antarctic ice sheet, the ice temperature usually increases with depth, so a hot-point drill will penetrate faster with increasing borehole depth. More power is required to reach the desired ROP for cold glaciers than for temperate glaciers. Similarly, drilling in extraterrestrial planets, such as Saturn's moon, Enceladus, and Jupiter's moon, Europa, will consume more energy in warming the ice to its melting point than for drilling in a terrestrial environment.

In summary, thin water film, low flow velocity and low waterfilm temperature can always result in a high penetration rate and small heat disturbance range. However, the BCF, thermal head power (or temperature) and ice temperature have mixed influence on the variables mentioned above. For example, an increase in BCF under PDC can result in a thinner water film and lower water-film temperature, which helps to increase ROP. Conversely, increasing the $\mathrm{BCF}$ can also lead to a faster flow velocity. The increase in ROP with BCF is the combined effect of these variables.

\section{Conclusions}

In this study, a thermal model was developed to evaluate the drilling performance of hot-point drills in ice. Under both PDC and TDC, the model was implemented using COMSOL Multiphysics 5.3a software to determine the effects of thermal head shape, cone angle, BCF, thermal head power (or temperature) and ice temperature. Based on the obtained calculation results, the following conclusions are summarized:

(1) The desired shape of the thermal head for the highest ROP is sphere under PDC and cone under TDC. The effect of thermal head shape on ROP is significantly lower compared with that of other variables; thus, the shape of the thermal head is not a critical factor to consider in the design of hot-point drills.

(2) A thermal head with a long cone shape is more aggressive than a thermal head with a short cone shape, but the increase in ROP is not big. In designing a conical thermal head, small cone angle can only improve the ROP a little.

(3) The ROP increases with BCF, but the effect of BCF decreases with the increase in BCF. It is recommended that a dead weight should be added to a lightweight hot-point drill while the axial load of a heavy hot-point drill should be reduced to prevent the tilting of the borehole. Typically, a specific BCF of $35 \mathrm{~N} \mathrm{~cm}^{-2}$ is high enough to achieve the desired ROP.

(4) The increase in power (under PDC) or temperature (under TDC) of the thermal head leads to an increase in ROP. Hence, in engineering practice, increasing the power or temperature of the thermal head is the most common and simplest method to apply for obtaining a high ROP.

(5) Irrespective of the heated boundary condition used for thermal heads, the ROP increases with increasing ice temperature. Ice temperature is an uncontrollable environmental factor that exists during drilling. It is reasonable to use a hypothetical ice temperature profile of targeted glaciers or ice sheets to design and manufacture hot-point drills, so that the required power of the thermal head and the ROP of the hot-point drill during the actual drilling can be estimated more precisely.

Acknowledgments. This work was supported by the Ministry of Science and Technology of the People's Republic of China (grant No. 2016YFC1400300), the National Nature Science Foundation of China (grant No. 41706214 and grant No. 41941005) and the Program for Jilin University Science and Technology Innovative Research Team (grant No. 2017TD-24). We thank the anonymous reviewers for their fruitful suggestions, useful comments and editing.

\section{References}

Aamot HWC (1967) Heat transfer and performance analysis of a thermal probe for glaciers. USA CRREL Technical Report, 194.

Bahrami PA and Wang TG (1987) Analysis of gravity and conduction-driven melting in a sphere. Journal of Heat Transfer 109(3), 806-809. doi: 10.1115/ 1.3248166

Batchelor GK (1967) An Introduction to Fluid Dynamics. Cambridge: Cambridge University Press.

Bejan A and Tyvand PA (1992) The pressure melting of ice under a body with flat base. Journal of Heat Transfer 114(2), 529-531. doi: 10.1115/ 1.2911310

Benson T and 9 others (2014) IceCube enhanced hot water drill functional description. Annals of Glaciology 55(68), 105-114. doi: 10.3189/2014AoG68A032

Birth FS (1975) Conductive heat flow anomalies over a hot spot in a moving medium. Journal of Geophysical Research 80(35), 4825-4827. doi: 10.1029/ JB080i035p04825

Chen W, Chen Z, Zhao Y, Sun F and Gong M (2008) Analysis of $\Delta \mathrm{T}$ driven contact melting of phase change material around a horizontal cylinder. Energy Conversion and Management 49(5), 1002-1007. doi: 10.1016/j. enconman.2007.10.001

Chen W, Cheng S, Luo Z and Zhu H (1994) An analytical solution of melting around a moving elliptical heat source. Journal of Thermal Science 4(1), 2327. doi: 10.1007/BF02653241

Chen W, Li H, Gao M, Liu Z and Sun F (2005) The pressure melting of ice around a horizontal elliptical cylinder. Heat and Mass Transfer 42(2), 138143. doi: 10.1007/s00231-005-0003-8

Dachwald B and 10 others (2020) Key technologies and instrumentation for subsurface exploration of ocean worlds. Space Science Reviews 216(5), 83. doi: $10.1007 /$ s11214-020-00707-5

Emerman SH and Turcotte DL (1983) Stokes's problem with melting. International Journal of Heat and Mass Transfer 26(11), 1625-1630. doi: 10.1016/S0017-9310(83)80082-9

Fomin SA and Cheng SM (1991) Optimization of the heating surface shape in the contact melting problem. In Dulikravich GS eds. Proceedings of Third International Conference on Inverse Design Concepts and Optimization in Engineering Sciences, 23 October-25 October 1991, Washington DC, 136-143.

Gerrard JAF, Perutz MF and Roch A (1952) Measurements of the velocity distribution along a vertical line through a glacier. Proceedings of the Royal Society of London Series A 213(1115), 546-558. doi: 10.1098/rspa.1952.0144 Gillet F (1975) Steam, hot-water and electrical thermal drills for temperate glaciers. Journal of Glaciology 14(70), 171-179. doi: 10.3189/S0022143000013484

Groulx D and Lacroix M (2003) Effects of convection and inertia on close contact melting. International Journal of Thermal Sciences 42(12), 10731080. doi: 10.1016/S1290-0729(03)00096-6

Groulx D and Lacroix M (2007) Study of the effect of convection on close contact melting of high Prandtl number substances. International Journal of Thermal Sciences 46(3), 213-220. doi: 10.1016/j.ijthermalsci.2006.04.017

Hirata T, Makino Y and Kaneko Y (1991) Analysis of close-contact melting for octadecane and ice inside isothermally heated horizontal rectangular capsule. International Journal of Heat and Mass Transfer 34(12), 30973106. doi: 10.1016/0017-9310(91)90079-T 
Hooke Rle B (1976) University of Minnesota ice drill. Ice-Core Drilling: Proceeding of the Symposium in University of Nebraska Lincoln, 28 August-30 August 1974, Lincoln, NB, USA, 47-57.

Horne MF (2017) Thermal probe design for Europa sample acquisition. Acta Astronautica 142, 29-36. doi: 10.1016/j.actaastro.2017.10.015

Hu Y, Huang S and Shi M (1999) A generalized analysis of close-contact melting processes in two-dimensional axisymmetric geometries. International Communications in Heat and Mass Transfer 26(3), 339347. doi: 10.1016/S0735-1933(99)00020-2

Jackson F (1965) Moving heat sources with change of phase. Journal of Heat Transfer 87(3), 329-332. doi: 10.1115/1.3689108

Jansen G and Stepnewski DD (1973) Fast reactor fuel interactions with floor material after a hypothetical core meltdown. Nuclear Technology 17(1), 8596. doi: 10.13182/NT73-A31259

Kasser P (1960) Ein leichter thermischer Eisbohrer als Hilfsgerät zur Installation von Ablationsstangen auf Gletschern. Geofisica Pura e Appliclla 45(1), 97-114. doi: 10.1007/BF01996577

Kumano H, Saito A, Okawa S, Takeda K and Okuda A (2005a) Study of direct contact melting with hydrocarbon mixtures as the PCM. International Journal of Heat and Mass Transfer 48(15), 3212-3220. doi: doi:10.1016/j. ijheatmasstransfer.2005.01.040

Kumano H, Saito A, Okawa S and Yamada Y (2005b) Direct contact melting with asymmetric load. International Journal of Heat and Mass Transfer 48 (15), 3221-3230. doi: 10.1016/j.ijheatmasstransfer.2005.01.041

LaChapelle E (1963) A simple thermal ice drill. Journal of Glaciology 4(35), 637-642. doi: 10.3189/S002214300002815X

Logan SE (1974) Deep self-burial of radioactive wastes by rock-melting capsules. Nuclear Technology 21(2), 111-124. doi: 10.13182/NT74-A31367

Lorenz RD (2012) Thermal drilling in planetary ices: an analytic solution with application to planetary protection problems of radioisotope power sources. Astrobiology 12(8), 799-802. doi: 10.1089/ast.2012.0816

Marsh BD (1978) On the cooling of ascending andesitic magma. Philosophical Transactions of the Royal Society of London, Series A: Mathematical, Physical and Engineering Sciences 288(1355), 611-625. doi: 10.1098/rsta. 1978.0037

Mayer P and Moaveni S (2008) Close-contact melting as a subtractive machining process. The International Journal of Advanced Manufacturing Technology 37(9), 980-995. doi: 10.1007/s00170-007-1031-y

Moallemi MK and Viskanta R (1985) Melting around a migrating heat source. Journal of Heat Transfer 107(2), 451-458. doi: 10.1115/1.3247436

Moallemi MK, Webb B and Viskanta R (1986) An experimental and analytical study of close-contact melting. Journal of Heat Transfer 108(4), 894899. doi: $10.1115 / 1.3247030$

Nizery A (1951) Electrothermic rig for the boring of glaciers. Transactions AGU 32(1), 66-72. doi: 10.1029/TR032i001p00066

Pudovcin MA, Salamatin AN, Fomin SA and Chistyakov VK (1988) Effect of the working surface shape of a thermal drill on hot-point ice boring performance. Journal of Soviet Mathematics 43(3), 2496-2505. doi: 10.1007/ BF01095659

Roy SK and Sengupta S (1987) The melting process within spherical enclosures. Journal of Heat Transfer 109(2), 460-462. doi: 10.1115/1.3248104

Roy SK and Sengupta S (1990) A generalized model for gravity-assisted melting in enclosures. Journal of Heat Transfer 112(3), 804-808. doi: 10.1115/1. 2910464

Salamatin AN, Fomin SA, Chistyakov VK and Chugunov VA (1984) Mathematical description and calculation of contact melting. Journal of
Engineering Physics and Thermophysics 47(3), 1071-1077. doi: 10.1007/ BF00873722

Schïller K and Kowalski J (2017) Spatially varying heat flux driven close-contact melting - a Lagrangian approach. International Journal of Heat and Mass Transfer 115, 1276-1287. doi: 10.1016/j.ijheatmasstransfer.2017.08.092

Schüller K and Kowalski J (2019) Melting probe technology for subsurface exploration of extraterrestrial ice - critical refreezing length and the role of gravity. Icarus 317, 1-9. doi: doi:10.1016/j.icarus.2018.05.022

Schüller K, Kowalski J and Råback P (2016) Curvilinear melting - a preliminary experimental and numerical study. International Journal of Heat and Mass Transfer 92, 884-892. doi: 10.1016/j.ijheatmasstransfer.2015.09.046

Shreve RL (1962) Theory of performance of isothermal solid-nose hotpoints boring in temperate ice. Journal of Glaciology 4(32), 151-160. doi: $10.3189 /$ S0022143000027362

Stone WC, Hogan B, Siegel VL, Lelievre S and Flesher C (2014) Progress towards an optically powered cryobot. Annals of Glaciology 55(65), 1-13. doi: 10.3189/2014AoG65A200

Sukhanov LA, Morev VA and Zotikov IA (1974) Potativnye ledovye elektrobury [Portable thermo-electric ice drills]. In: Akademiya nauk SSSR. vol. 23. Institut geografii. Materialy gliatsiologicheskikh Issledovanii [Academy of Sciences of the USSR. Institute of Geography. Data of Glaciological Studies], 234-238 (in Russian).

Talalay PG and 5 others (2019) Thermal tips for ice hot-point drilling: experiments and preliminary thermal modeling. Cold Regions Science and Technology 160, 97-109. doi: 10.1016/j.coldregions.2019.01.015

Talalay PG (2020) Thermal Ice Drilling Technology. Singapore: Springer Singapore.

Talalay PG, Zagorodnov VS, Markov AN, Sysoev MA and Hong J (2014) Recoverable autonomous sonde (RECAS) for environmental exploration of Antarctic subglacial lakes: general concept. Annals of Glaciology 55 (65), 23-30. doi: 10.3189/2014AoG65A003

Toshiyuki M and Giedt WH (1982) Heat transfer from elliptical cylinder moving through an infinite plate applied to electron beam welding. International Journal of Heat and Mass Transfer 25(6), 807-814. doi: 711 10.1016/0017-9310(82)90093-X

Treffer $\mathbf{M}$ and 7 others (2006) Preliminary studies concerning subsurface probes for the exploration of icy planetary bodies. Planetary and Space Science 54 (6), 621-634. doi: 10.1016/j.pss.2006.02.001

Weinberg BP (1912) Der elektrische Eisbohrer. Zeitschrift für Gletscherkunde 8, 214-217.

Weiss $\mathbf{P}$ and 5 others (2008) Study of a melting drill head for the exploration of subsurface planetary ice layers. Planetary and Space Science 56(9), 12801292. doi: $10.1016 /$ j.pss.2008.04.004

Wirtza $\mathbf{M}$ and Hildebrandt $\mathbf{M}$ (2016) IceShuttle Teredo: an ice-penetrating robotic system to transport an exploration AUV into the ocean of Jupiter's moon Europa. 67th International Astronautical Congress (IAC), September, 2016. Guadalajara, Mexico, 26-30.

Yoo H (2000) Analytical solutions to the unsteady close-contact melting on a flat plate. International Journal of Heat and Mass Transfer 43(8), 14571467. doi: 10.1016/S0017-9310(99)00221-5

Yoo H, Hong H and Kim CJ (1998) Effects of transverse convection and solid-liquid density difference on the steady close-contact melting. International Journal of Heat and Fluid Flow 19(4), 368-373. doi: 10. 1016/S0142-727X(98)10011-5

Zotikov IA, Kapitsa AP, Kudriavtsev Ye V and Sukhanov LA (1974) Thermal drilling of the glacier. CRREL Report TL, 414 . 